\title{
Geri Dönüşümden Palet Üretiminde Etken Parametrelerin Taguchi Yöntemi İle Deneysel Tespiti
}

\author{
Mustafa Soylak $^{1 *}$, Şevval Zümrüt ${ }^{2}$ \\ $1^{*}$ Erciyes Üniversitesi, Havacıllk ve Uzay Bilimleri Fakültesi, Uçak Gövde Motor Bakım Bölümü, Kayseri, Türkiye, (ORCID: 0000-0002-5617-5913), \\ soylakm@erciyes.edu.tr \\ 2 Kilim Mobilya A.Ş., Kayseri, Türkiye, szumrut@kilimmobilya.com.tr
}

(Uluslararası Araştırma-Geliştirme ve Tasarım Konferansı - 15-18 Aralık 2021)

(DOI: 10.31590/ejosat.1040763)

ATIF/REFERENCE: Soylak, M. \& Zümrüt, Ş. (2021). Geri Dönüşümden Palet Üretiminde Etken Parametrelerin Taguchi Yöntemi İle Deneysel Tespiti. Avrupa Bilim ve Teknoloji Dergisi, (32), 548-552.

$\ddot{O ̈ z}$

Bu çalışmada, yük taşıma maksatlı kullanımı olan palet üretiminde geri dönüşümden gelen atık talaşın kullanılması esnasında en önemli etken parametrenin ne olacağının tespiti hedeflenmiştir. Ahşap kompozitlerinden olan ve çalışma kapsamında oluşturulan sunta malzemesinin imalatında yüksek mukavemet elde edilmesine yönelik etken parametrenin tespiti Taguchi yöntemi ile gerçekleştirilmiştir. İstenen mukavemet değerini elde etmek için önemli olduğu düşünülen 3 faktör içinden en önemli etkiye sahip olanı Taguchi L8 deney dizisi kullanılarak tespit edilmiştir. Çalışma kapsamında üretim esnasında gerçekleşen basınç, karışım oranı ve baskı süresi incelenmeye değer etkenler olarak belirlenmiştir. Belirlenen bu 3 parametrenin 2 farklı seviyesi denenerek deneysel çalışma yapılmıştır. 3 parametreli ve 2 seviyeli olacak şekilde $2^{3}=8$ deney ile çalışma tamamlanmıştır. Çalışma sonucunda geri dönüşümden elde edilen sunta talaşı kullanılarak palet üretiminde en önemli etkenin ne olduğu tespit edilmiştir. Basınç, karışım oranı ve baskı süresi etkenlerinden hiçbirisinin tek başına diğerinden daha önemli oranda bir etkisi olmadığı ve ortak etkileri sonucu istenen mukavemet değeri elde edildiği sonucuna ulaşılmıştır.

Anahtar Kelimeler: Taguchi, Palet, Mekatronik, Mobilya.

\section{Experimental Determination of Effective Parameters in Pallet Production from Recycling by Taguchi Method}

\begin{abstract}
In this study, it is aimed to determine what the most important factor will be during the use of waste sawdust from recycling in pallet production, which is used for load carrying purposes. The determination of the effective parameter for obtaining high strength in the manufacture of the chipboard material, which is one of the wood composites and formed within the scope of the study, was carried out by the Taguchi method. Among the 3 factors that are thought to be important to obtain the desired strength value, the one with the most important effect was determined using the Taguchi L8 test series. Within the scope of the study, the pressure during the production, the mixing ratio and the operation time were determined as factors worth examining. Experimental study was carried out by trying 2 different levels of these 3 parameters. The study was completed with $2^{3}=8$ experiments with 3 parameters and 2 levels. As a result of the study, the most important factor in pallet production was determined by using chipboard shavings obtained from recycling. It has been concluded that none of the factors of pressure, mixing ratio and printing time have a more significant effect than the other and the desired strength value is obtained as a result of their joint effects.
\end{abstract}

Keywords: Taguchi, Pallet, Mechatronics, Furniture.

\footnotetext{
${ }^{*}$ Sorumlu Yazar: Mustafa Soylak, Erciyes Üniversitesi, Havacılık ve Uzay Bilimleri Fakültesi, Uçak Gövde Motor Bakım Bölümü, Kayseri, Türkiye, (ORCID: 0000-0002-5617-5913),soylakm@erciyes.edu.tr
} 


\section{Giriş}

Lojistik uygulamalarda ürünlerin taşınması ve depolanması esnasında sürecin kolaylaşması ve ürünlerin zarardan korunması için ürün altlarında kullanılan taşıyıcı elemana palet ismi verilmektedir (1). Palet imalatında kullanılan ahşap elemanlar birçok ebatlama işlemi sonrasında istenen nihai şekline ulaşmaktadırlar. $\mathrm{Bu}$ süreç her bir ürün için yaşanmaktadır ve beraberinde yüksek enerji kayıpları, yüksek maliyetli ebatlama makinelerine gereksinim duyulması, çok miktarda fire oranı ve tüm bu etkenlere bağlı ciddi ekonomik kayıpları getirmektedir. Araştırmacılar bu çalışma kapsamında, ağaçların kesilmesi ile elde edilen kütük malzemeler yerine, mümkün olan en yüksek oranda geri dönüşüm ahşap talaşı içeren sunta malzemenin palet üretiminde kullanılması imkanını araştırmışlardır. Yapılan incelemeler göstermiştir ki; kontrolsüz tüketim sonucunda masif mobilya hammaddesi olan ağaçların kesimine bağlı olarak yıllık $\% 2$ oranında ormanlık alan azalması gerçekleşmektedir $(1,2) \mathrm{Bu}$ durum alternatif mobilya üretim malzemelerinden olan ahşap kompozitlerinin geliştirilmesinde önemli bir gerekçe olmuştur. Yapıştırıcı ve ahşap parçacıklarının basınç altında birleştirilmesi yöntemi ilk olarak 1936 yılında gerçekleştirilmiştir (3). Farklı boyutlara sahip ahşap malzemelerin geliştirilen kompozit içinde kullanım imkanları bilim insanları tarafından araştırılmıştır (4). Özellikle ikinci dünya savaşı sonrasında uygun yapıştırıcı teknolojisinin geliştirilmesi ile dünya genelinde sunta malzeme türlerinin ar-ge çalışması önemli oranda artış göstermiştir (5-6, 3). Özellikle modüler mobilya sektörü için ilk çözüm ürünü olarak sunta malzeme geliştirilmiştir. Sunta, istenen boyutlarda parçacıklara ayrılan ağaç malzemenin sentetik reçinelerle karıştırılarak, 1Sı ve basınç altında birleştirilmesi ile üretilmektedir (5). $\mathrm{Bu}$ birleştirme esnasında talaş malzeme arasında bulunan boşluklar giderilemediği için sunta malzemenin su tutma özelliği yüksektir. $\mathrm{Bu}$ ise mukavemet kaybı ile sonuçlanmaktadır. Bu sebeple henüz sunta imalatı gerçekleşmeden talaş malzemenin kurutularak imalat için gerekli nem seviyesinin oluşturulması gerekmektedir.

Sunta ve türevleri olan ahşap kompozitleri talep edilen özellikleri mekanik ve fiziksel yapısı ile karşılamaları, yüzey formunun ayarlanabilir hassasiyette olmas1, talep edilen boyutlarda üretilme ve sonrasında daha küçük boyutlarda ebatlanabilmesi, farklı birleştirme imkanlarına uyumlu olması (vidalama, yapıştırma, çivileme, mekanik şekil bağlantıları, vb.), karışımına katılan ilave malzemeler ile farklı ilave özellikler kazandırılabilmesi (yanma dayanımı, su tutma özelliğinde ayarlama kabiliyeti, çevresel şartlara dayanım, vb.), küçük parçalıda olsa ahşap atıklarının üretiminde kullanılabiliyor olması ve karışımında kullanılan ürünlerden daha düşük maliyetle üretilebiliyor olması sebebiyle yaygın üretime sahip bir üründür (7). Bu çalışma kapsamında Taguchi yöntemi kullanılarak bir dizi deney gerçekleştirimiştir. Böylece deneylerin baştan tasarlanması ve en az deneyle en doğru sonuca ulaşılması hedeflenmiştir. Deneysel tasarımda en önemli aşama hedef değerin elde edilebilmesi için etken parametrelerin en doğru şekilde tespit edilmesidir. Bunun için çok iyi bir gözlemleme süreci gereklidir. $\mathrm{Bu}$ tespit aşamasında tecrübe de önemli rol almaktadır. Burada amaç hedef değere ulaşılabilmesi yolunda kontrol edilemeyen parametrelerin olumsuz etkilerinin kontrol edilebilen parametrelerin etkileri ile ortadan kaldırılmasıdır. $\mathrm{Bu}$ şekilde gerçekleşen ürün ve uygulama tasarımı gürbüz tasarım olarak isimlendirilmektedir, kontrolü mümkün olmayan ve sonucu kontrolsüz şekilde olumsuz etkileyen parametrelere ise gürültü denilmektedir. Ayrıca, çalışma esnasında etken parametrelerin ortak etkileri de söz konusudur (8). Araştırmacılar tarafından farklı problemlerin çözümü ve farklı tasarım süreçleri için doğru parametrelerin tespiti amacıyla deneylerin tasarımı gerçekleştiren Taguchi yöntemi bilimsel platformda incelenmektedir. Coşkun, S. ve arkadaşları gerçekleştirdikleri çalışmada mekanik 1sı pompası atık 1S1 geri kazanımı ve optimizasyonu konusunu Taguchi yöntemi kullanarak incelemişlerdir. Kompresör hızı, atık su sıcaklığı ve akış hızını etken parametreler olarak incelemişlerdir. Yapay sinir ağları kullanılarak elde edilen sonuçlarla Taguchi yöntemi kullanılarak elde edilen sonuçlar karşılaştırılmıştır ve bu deneysel çalışmanın sonunda atık ısının geri kazanımı için mekanik 1S1 pompası kullanılması ile sistem performansını arttırmanın mümkün olduğu bulunmuştur (9). Dongxia, Y., ve arkadaşları gerçekleştirdikleri çalışmada lazer kaynağı için optimizasyon çalışması yapmışlardır. Al-Mg alaşımı için dolgulu tel ve lazer kaynağı uygulaması yapılarak, bu çalışma için etkin parametrelerin tespiti gerçekleştirilmiştir (10). Asghari, I. ve Esmaeilzadeh, F. ise belirledikleri kimyasal süreç içinde etkin parametrelerin tespitini Taguchi yöntemi ile gerçekleştirmişlerdir (11). Canel, T. ve arkadaşları gerçekleştirdikleri bilimsel çalışmada Taguchi yönteminin endüstriyel kullanımına örnek olacak nanosaniye lazerin parametre optimizasyonunu gerçekleştirmişlerdir, doğrulama deneyleri ile sonuçların Taguchi yöntemi ile uyumunu göstermişlerdir (12). Soylak, M., ve arkadaşları, uçak kanat tasarımı için önemli faktörleri Taguchi yöntemi ile belirleme amaçlı bir çalışma gerçekleştirerek, en önemli parametrenin Reynold Sayısı olduğunu belirlemişlerdir (13). L8, L16, L27, vb. diziler kullanılarak deneyler yapılmakta, belirlenen parametrelerin ve ortak etkilerinin sonuca etkisinin tespiti amaciyla A, B, C ile ifade edilen faktörlerin olduğu, bu faktörlerin her birinin 2 farklı değer aldığı bir uygulamada; faktör sayısı n olan deneyler düzey sayısı 2 olacak şekilde gerçekleşmekte ve $2^{\text {n }}$ deney yapılması gerekmektedir. Mevcut çalışmada 3 etken parametre tespit edilmiş olup, her etken parametrenin 2 farklı değeri alınmaktadır. Bu durumda; A, B ve $\mathrm{C}$ değerleri için deney sayıs $=2^{\mathrm{n}}=2^{3}=8^{\prime}$ dir. L8 deney dizisi kullanılarak bu çalışma gerçekleştirilmiştir. Çalışma sonucunda hedef değer olan yüksek mukavemet sonucuna ulaşılabilmesi için en önemli etken parametre tespiti gerçekleştirilmiştir.

\section{Materyal ve Metot}

\subsection{Deneysel Çalışma}

Çalışma kapsamında 300mmx100mm ebatlarında talaş malzemeden sunta imalatı gerçekleştiren ve deneysel numune üretimi yapabilecek bir üretim sistemi oluşturuldu (Şekil 1.). Bu sistem değişken basınçlarda baskı yapılabilen ve sıcaklığ kontrol altında tutulabilen bir kalıp ünitesine sahiptir. Sistemin bu esnekliği sayesinde farklı basınç, sıcaklık alternatiflerinin deneysel incelemesi mümkün olmuştur. 


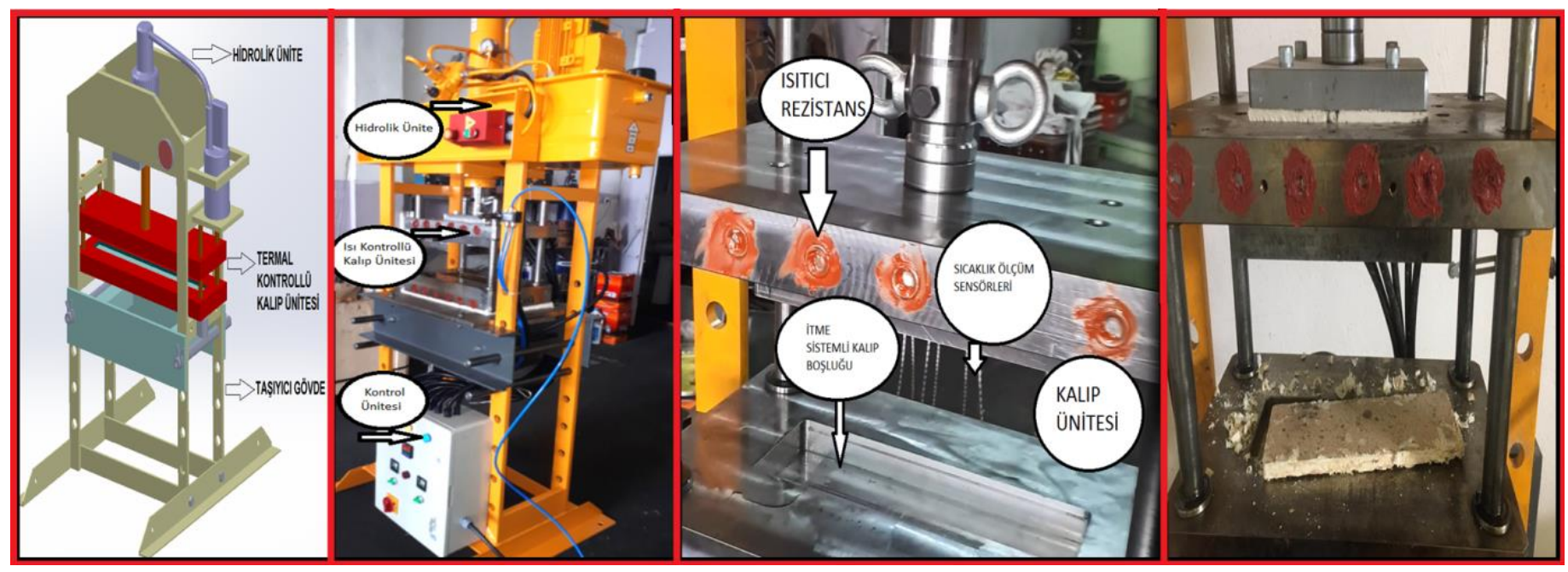

Şekil 1. Deneysel Sistem

Oluşturulan ahşap esaslı kompozit malzemeler 3 nokta eğme deneyine tabi tutulmuştur (Şekil 2.).

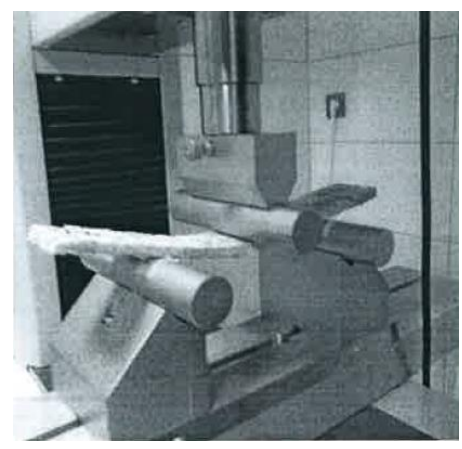

Şekil2. 3 Nokta Ĕgme Deneyi İçin Deneysel Sistem

Çalışma kapsamında oluşturulan ahşap kompozitlerinden alınan numuneler üzerinde ahşap esaslı levhalar-eğilme dayanımı ve elastikiyet modülü tayini başlıklı test uygulaması (TS EN 310) gerçekleştirilmiştir. Deneysel çalışma esnasında 8 levhadan birer numune alınmıştır ve kullanılan numunelerin genişliği $50 \mathrm{~mm}$ ve uzunluğu 300 mm' dir. Pres sıcaklığı: $100{ }^{\circ} \mathrm{C}$ olarak uygulanmıştır. Ortalama yoğunluk değeri $0,77 \mathrm{gr} / \mathrm{cm}^{3}$ olup, deneysel numunelerde ölçülen ortalama rutubet değeri ise \%8.7 olarak ölçülmüştür. Deneysel çalışma esnasında üç önemli parametreye ait iki farklı değer alt değer ve üst değer olarak alınmıştır. $\mathrm{Bu}$ üç önemli parametre ve çalışmada kullanılan birimleri sıras1 ile; pres basinc1 (Bar), pres sıkıştırma süresi (dk) ve lignoselülozik malzeme-tutkal karışım oranı (\%) olarak tespit edilmiştir. Deneysel çalışma öncesi tüm örnekler 5 gün süre ile $20{ }^{\circ} \mathrm{C}$ ve $\% 65$ rutubet miktarında şartlandırılmıştır. Deneysel çalışma esnasında önceden belirlenen önemli parametrelere ait Tablo 1. ' de verilen alt ve üst değerler kullanılmıştır.
Tablo 1. Deneysel Çalışma Kapsamında İncelenen Parametreler ve Değerleri

\begin{tabular}{|c|c|c|c|}
\hline Tanımlar & Değişken & Düşük & Yüksek \\
\hline A & Basınç (Bar) & 100 & 150 \\
\hline B & Süre (dk) & 5 & 10 \\
\hline C & $\begin{array}{c}\text { Karışım Oranı } \\
\%\end{array}$ & $16 \%$ & $20 \%$ \\
\hline
\end{tabular}

Tablo 2. L8 Deney Tablosuna Uygun Her Deneyin Veri Dăğlımı

\begin{tabular}{|c|c|c|c|}
\hline & A & B & C \\
\hline & Basınç & Süre & $\begin{array}{c}\text { Karısım } \\
\text { Oranı }\end{array}$ \\
\hline Deney Sıra No 1 & 100 & 5 & 16 \\
\hline Deney Sıra No 2 & 100 & 5 & 20 \\
\hline Deney Sıra No 3 & 100 & 10 & 16 \\
\hline Deney Sıra No 4 & 100 & 10 & 20 \\
\hline Deney Sıra No 5 & 150 & 5 & 16 \\
\hline Deney Sıra No 6 & 150 & 5 & 20 \\
\hline Deney Sira No 7 & 150 & 10 & 16 \\
\hline Deney Sıra No 8 & 150 & 10 & 20 \\
\hline
\end{tabular}

Deneysel çalışma esnasında ilgili parametrelerin alt ve üst değerleri kullanılarak Tablo 3.' te verilen sonuçlar ölçülmüştür. $\mathrm{Bu}$ sonuçlar sırası ile; tam kuru yoğunluk $\left(\mathrm{gr} / \mathrm{cm}^{3}\right)$, maksimum kuvvet $(\mathrm{N})$, elastikiyet modülü $\left(\mathrm{N} / \mathrm{mm}^{2}\right)$, eğilme dayanımı $\left(\mathrm{N} / \mathrm{mm}^{2}\right)$ ' dir. Eğilme dayanımı sonucu Taguchi deneysel tasarım çalışması kapsamında hedef değer olarak ele alınmıştır. 


\section{Araştırma Sonuçları}

Çalışma kapsamında L8 deney dizisine uygun bir seri deney gerçekleştirilmiştir. Bu deneylere ait sonuç değerleri Tablo 3.' te verilmişsir.

Tablo 3. Deneysel Çalışma Sonucu Ölçülen Sonuç Değerler

\begin{tabular}{|l|l|l|l|l|}
\hline $\begin{array}{l}\text { Numune } \\
\text { No: }\end{array}$ & $\begin{array}{l}\text { Tam kuru } \\
\text { yoğunluk } \\
\left({\left.\mathrm{gr} / \mathrm{cm}^{3}\right)}^{3}\right.\end{array}$ & $\begin{array}{l}\text { Maksimum } \\
\text { Kuvvet }(\mathrm{N})\end{array}$ & $\begin{array}{l}\text { Elastikiyet } \\
\text { Modülü } \\
\left(\mathrm{N} / \mathrm{mm}^{2}\right)\end{array}$ & $\begin{array}{l}\text { Ĕgilme } \\
\text { Dayanımı } \\
\left(\mathrm{N} / \mathrm{mm}^{2}\right)\end{array}$ \\
\hline 1 & 0.80 & 43.03 & 350.91 & 6.38 \\
\hline 2 & 0.97 & 133.79 & 1352.63 & 7.36 \\
\hline 3 & 0.93 & 54.44 & 239.86 & 5.81 \\
\hline 4 & 0.58 & 189.77 & 1431.62 & 9.04 \\
\hline 5 & 0.76 & 62.41 & 317.57 & 8.75 \\
\hline 6 & 0.99 & 39.61 & 98.85 & 5.45 \\
\hline 7 & 0.91 & 94.00 & 510.58 & 7.41 \\
\hline 8 & 0.79 & 55.14 & 171.02 & 7.57 \\
\hline
\end{tabular}

Tablo3.' te verilen deneysel sonuçlar L8 Değerler tablosunda (Tablo 4.) bulunan ilgili kutucuklara aktarılarak parametrelere ait etki değerleri tespit edilmiştir.

Tablo 4. L8 Dĕgerler Tablosu

\begin{tabular}{|c|c|c|c|c|c|c|c|c|c|c|c|c|c|c|c|}
\hline \multirow{3}{*}{ Numarası } & \multirow{3}{*}{$\begin{array}{l}\text { Gözlem } \\
\text { Değereri }\end{array}$} & \multicolumn{2}{|c|}{$\underline{\mathbf{A}}$} & \multicolumn{2}{|c|}{$\underline{\mathbf{B}}$} & \multicolumn{2}{|c|}{$\underline{\mathrm{C}}$} & \multicolumn{2}{|c|}{$\underline{\underline{\mathrm{AB}}}$} & \multicolumn{2}{|c|}{$\underline{\underline{\mathrm{AC}}}$} & \multirow{2}{*}{\multicolumn{2}{|c|}{$\underline{\mathrm{BC}}$}} & \multicolumn{2}{|c|}{$\underline{\mathrm{ABC}}$} \\
\hline & & & & & & & & & & & & & & & \\
\hline & & 1 & $\underline{2}$ & $\underline{1}$ & $\underline{2}$ & $\underline{1}$ & $\underline{2}$ & $\underline{1}$ & $\underline{2}$ & $\underline{1}$ & $\underline{2}$ & $\underline{1}$ & $\underline{2}$ & $\underline{1}$ & 2 \\
\hline 1 & 6.38 & 6.38 & & 6.38 & & 6.38 & & & 6.38 & & 6.38 & & 6.38 & 6.38 & \\
\hline$\underline{2}$ & $\underline{7.36}$ & 7.36 & & $\underline{7.36}$ & & & 7.36 & & $\underline{7.36}$ & $\underline{7.36}$ & & 7.36 & & & 7.36 \\
\hline$\frac{3}{3}$ & $\underline{5.81}$ & $\underline{5.81}$ & & & 5.81 & $\underline{5.81}$ & & $\underline{5.81}$ & & & $\underline{5.81}$ & $\underline{5.81}$ & & & 5.81 \\
\hline 4 & 9.04 & 9.04 & & & 9.04 & & 9.04 & $\underline{9.04}$ & & $\underline{9.04}$ & & & $\underline{9.04}$ & $\underline{9.04}$ & \\
\hline$\underline{5}$ & 8.75 & & $\underline{8.75}$ & $\underline{8.75}$ & & 8.75 & & $\underline{8.75}$ & & $\underline{8.75}$ & & & $\underline{8.75}$ & & 8.75 \\
\hline$\underline{6}$ & $\underline{5.45}$ & & 5.45 & $\underline{5.45}$ & & & $\underline{5.45}$ & $\underline{5.45}$ & & & $\underline{5.45}$ & $\underline{5.45}$ & & $\underline{5.45}$ & \\
\hline 7 & 7.41 & & $\underline{7.41}$ & & 7.41 & 7.41 & & & 7.41 & 7.41 & & 7.41 & & 7.41 & \\
\hline$\underline{8}$ & 7.57 & & 7.57 & & 7.57 & & 7.57 & & 7.57 & & 7.57 & & 7.57 & & 7.57 \\
\hline Toplam & $\underline{57.77}$ & $\underline{28,59}$ & $\underline{29,18}$ & $\underline{27,94}$ & $\underline{29,93}$ & $\underline{28,35}$ & $\underline{29,42}$ & $\underline{29,05}$ & $\underline{28,72}$ & $\underline{32,56}$ & $\underline{25,21}$ & $\underline{26,03}$ & $\underline{31,74}$ & $\underline{28,28}$ & $\underline{29,49}$ \\
\hline Test Savis1 & $\underline{8}$ & $\underline{4}$ & 4 & $\underline{4}$ & 4 & 4 & 4 & $\underline{4}$ & $\underline{4}$ & $\underline{4}$ & $\underline{4}$ & $\underline{4}$ & 4 & $\underline{4}$ & $\underline{4}$ \\
\hline Ortalama & 7.22 & 7,14 & 7.29 & 6.98 & 7.48 & 7,08 & 7,35 & 7,26 & 7.18 & $\underline{8,14}$ & 6.45 & 6.50 & 7.93 & 7.07 & 7.37 \\
\hline Etki & & & & & .5 & & $\frac{1}{27}$ & & & & & & 43 & & \\
\hline Srralama & & & & & 2 & & 4 & & & & & & & & \\
\hline
\end{tabular}

Deneyler tamamlandiktan sonra herbir parametrenin etki seviyesi ve sayısal değer eşleşmesi Normal olasılık grafiği (NOG) üzerinde belirtilmiştir (Şekil 3.) . 


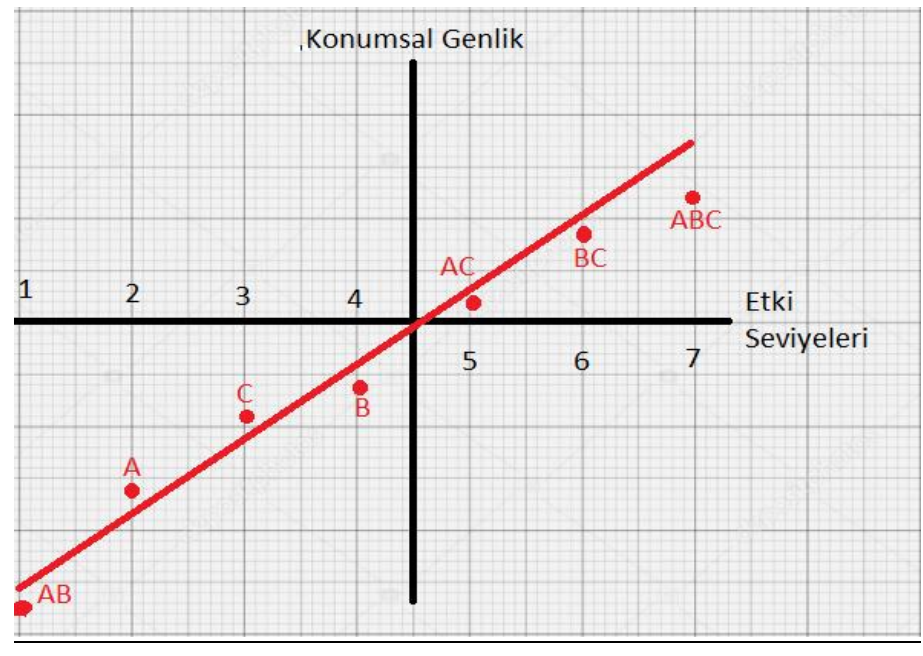

Şekil 3. Normal Olasılık Grafiği (NOG)

Normal olasılık grafiği incelenirken ortalama değer aralığından geçen çizgisel hattan en uzak olan değer en etkili değer olarak tespit edilmektedir. Bu çalışmada en etkili parametre ortak etki olarak tespit edilmiştir.

\section{Sonuç}

Bu çalışmada, Taguchi deney tasarımı yöntemi kullanılarak geri dönüşümden sunta malzeme imalatında belirlenen hedef değerlere ulaşmak için en etkin parametrenin tespiti yapılmıştır. Elde edilecek ürünün palet kullanımında kullanılacak olması parametrelerin tespitinde önemli kriter olmuştur. Taguchi L8 deney dizisi kullanılarak gerçekleştirilen deneyler sonucunda en etkin parametrenin tüm parametrelerin ortak etkisi olduğu sonucuna varılmıştır. Çalışmanın Taguchi yöntemi kullanılarak gerçekleştirilmesi ile deney süreci kısalmış, çok daha planlı ve az sayıda deneyle sonuç elde edilebilmiştir.

\section{Teşekkür}

Bu çalışma ERÜ BAP birimi tarafından FKA-2020-9629 kod'lu proje kapsamında desteklenmiştir.

\section{Kaynakça}

1. Akbulut, T. 2000. Yonga Levha Endüstrisi. Laminant Mobilya Dekorasyon Sanat Tasarımı Dergisi. 7.119-122.

2. Demirkır C., 2006. Kontrplak Üretimi Sırasında Oluşan Odunsu Atık ve Atık Materyallerin Yonga Levha Üretiminde Değerlendirilmesi. Yüksek Lisans Tezi. Karadeniz Teknik Üniversitesi. Fen Bilimleri Enstitüsü. Trabzon. 97s.

3. Kalaycığlu H., Özen R., 2012. Yonga levha Endüstrisi Ders Notları. Karadeniz Teknik Üniversitesi. Orman Fakültesi Yayınlar1. 89. Trabzon. 330s.

4. Güler C., 2001. Pamuk Saplarından Kompozit Levha Üretimi Olanaklarının Araştırılması.Doktora Tezi. Zonguldak Karaelmas Üniversitesi. Fen Bilimleri Enstitüsü. Bartın.150s.

5. Bozkurt A.Y., Göker Y., 1990. Yonga levha Endüstrisi, İstanbul Üniversitesi Orman Fakültesi Yayınları. İstanbul. Say1.3311. s.372, 263.
6. Şanıvar M., Zorlu İ., 1998. Ağaç İşleri Gereç Bilgisi. Marmara Üniversitesi Teknik Eğitim Fakültesi. İstanbul. 474 s.

7. Atar İ., 2012. Sertleştirici Türü, Üre kullanımı ve Depolama süresinin Yonga levhanın Kalite Özellikleri Üzerine Etkileri. Karadeniz Teknik üniversitesi. Fen Bilimleri Enstitüsü. Trabzon. 148s.

8. Soylak, M. (2000). Kalite Geliştirmede Deneysel Tasarım ve Taguchi Yöntemi, Y. Lisans Tezi, Erciyes Üniversitesi, Fen Bilimleri Enstitüsü, Makina Mühendisliği ABD, Kayseri.

9. Coşkun, S., Motorcu A.R., Yamankaradeniz N., Pulat E. (2012), Evaluation of Control Parameters Effects on System Performance with Taguchi Method in Waste Heat Recovery Application Using Mechanical Heat Pump. International Journal of Refrigeration, 35:4, 795-809.

10. Dongxia, Y., et. al. (2012). Optimization Of Weld Bead Geometry In Laser Welding With Filler Wire Process Using Taguchi's Approach. Optics \& Laser Technology. 44:7, 2020-2025.

11. Asghari, I., Esmaeilzadeh, F. (2012). Formation of Ultrafine Deferasirox Particles Via Rapid Expansion Of Supercritical Solution (RESS Process) Using Taguchi Approach. Int. J. Pharm. 20:1-2, 149-156.

12. Canel, T., et. al. (2012). Parameter Optimization of Nanosecond Laser for Micro drilling on PVC by Taguchi Method. Optics \& Laser Technology. 44:8, 2347-2353.

13. Soylak, M., et. al. (2018). Aircraft Wing Design at Low Speeds Using Taguchi Method. Aircraft Engineering and Aerospace Technology. 90:1, 51-55. 